\title{
PAIN RELIEF FROM PREGANGLIONIC INJURY TO THE BRACHIAL PLEXUS BY LATE INTERCOSTAL NERVE TRANSFER
}

\author{
J. BERMAN, P. ANAND, L. CHEN, M. TAGGART, R. BIRCH \\ From the Royal National Orthopaedic Hospital Trust, Stanmore, England
}

W e performed intercostal nerve transfer in 19 patients to relieve pain from preganglionic injury to the brachial plexus. The procedure was successful in 16 patients at a mean of 28.6 months (12 to 68) after the injury.

J Bone Joint Surg [Br] 1996;78-B:759-60.

Received 29 January 1996; Accepted 20 February 1996

Within a few days of preganglionic injury to the brachial plexus a characteristic severe pain usually occurs. A constant crushing or burning sensation is felt in the anaesthetic hand together with an episodic severe shooting pain which courses down the whole upper limb. The pain is worse in cold or wet weather and when the patient is otherwise ill or stressed. It disturbs sleep and rarely responds to standard analgesics or to any method of treatment short of operation on the spinal cord.

The natural history in those who do not have an operation has been described. Bonney (1959) followed 25 patients for a minimum of two years and found that the pain was worse in those who showed no functional recovery. Yeoman (1975) observed that severe pain persisted in 32 of his 46 patients with complete paralysis. Wynn Parry (1980) studied 122 patients with preganglionic injury for between three and 30 years; 112 experienced severe pain and in 48 of them it persisted for more than three years. In 28 the pain abated, in 15 within 12 months and in 11 between 12 and 36 months.

In 1984 we carried out an intercostal nerve transfer to the musculocutaneous nerve and the lateral root of the median nerve in a young woman with avulsion of the C5, C6 and $\mathrm{C} 7$ nerve roots in an attempt to regain elbow flexion and

J. Berman, MA, BN Bch, FRCA, Consultant Anaesthetist M. Taggart, RGN, RSCN, Research Co-ordinator

R. Birch, MChir, FRCS, Consultant Orthopaedic Surgeon

Peripheral Nerve Injury Unit, The Royal National Orthopaedic Hospital

Trust, Brockley Hill, Stanmore, Middlesex HA7 4LP, UK.

P. Anand, MD, MA, FRCP, Head of Academic Department of Neurology, St Bartholomew's and The Royal London Hospital, London E1 1BB, UK.

L. Chen, MD

Hua Shan Hospital, Shanghai, China.

Correspondence should be sent to Mr R. Birch.

(C)1996 British Editorial Society of Bone and Joint Surgery 0301-620X/96/51238\$2.00 provide some protective sensation in the distribution of the median nerve in the hand. Nine months after operation she had regained elbow flexion and told us that her pain had disappeared. This experience prompted us to use the operation for the treatment of intractable pain. Intercostal nerve transfers are valuable in restoring deltoid function and elbow flexion and may allow some sensory recovery in the hand, but useful motor recovery cannot be expected when the operation is performed more than one year after injury (Nagano et al 1989). We have performed these transfers at over one year after injury in 19 patients with the sole purpose of the relief of pain.

\section{PATIENTS AND METHODS}

In 11 of the 19 patients the diagnosis was confirmed by early operation and in the remainder by clinical evidence such as the extent of paralysis and sensory loss, the presence of a Bernard-Horner syndrome, persisting sensory action potentials in the trunk nerves of the limb and myelography or MRI. There were 17 men and two women; their mean age was 24 years (17 to 50). The dominant limb had been injured in seven. The cause of injury was a motor-cycle accident in 17, a pedal-cycle accident in one, and a fall in one. Seven patients had avulsion of five roots, six of four roots, four of three and two of two roots. Limited repair of the initial lesions by grafting was possible in five patients.

All patients experienced the onset of pain within 48 hours and considered it to be severe, interfering with every aspect of their daily life. It was felt in the elbow, forearm and hand and was described as a constant crushing sensation with a superimposed lightning-like shooting pain. All the patients spent two weeks in the Rehabilitation Unit of the Royal National Orthopaedic Hospital, but failed to respond to conventional analgesics, anticonvulsants such as carbamazepine and phenytoin or transcutaneous nerve stimulation.

At operation the T3, T4 and T5 intercostal nerves were transferred to the lateral cord or its derivative branches in nine patients and to the medial cord or its branches in ten. The choice of the recipient nerve was made on the basis of the location of the pain in the hand and the extent of recovery from either intact roots or nerve graft.

An independent assessment of each patient's pain was made by one of us before operation and at regular intervals 
thereafter. All 19 patients were followed up for a minimum of 18 months after operation. They described the extent of disturbance of work, study, hobbies and sporting pursuits, sleep and mood. The nature and the location of the pain were noted and the level of pain was assessed on a linear visual analogue scale (VAS). We recorded the analgesic requirement and side-effects, the effect of alcohol and other agents and the patient's own perception of the factors which mitigated pain. We classified the pain into four grades:

Severe. Constant disturbance of daily life, work, study and sleep (VAS 9 to 10).

Significant. Able to sleep but cannot work, study or enjoy hobbies (VAS 7 to 8).

Moderate. Able to work, but the pain is sometimes so severe as to require time off (VAS 4 to 6).

Mild. Aware of pain but able to lead a normal life (VAS 0 to 3 ).

\section{RESULTS}

Sixteen of the 19 patients reported worthwhile relief of pain at an average of eight months after intercostal transfer, ranging from three days to three years.

Before operation 18 patients had pain of grade 1 and one of grade 2. After operation ten had improvement of pain from grade 1 to grade 4,6 from grade 1 to grade 3 and one from grade 2 to grade 3; two showed no improvement.

\section{DISCUSSION}

There are two degrees of preganglionic injury to the brachial plexus; an intradural rupture of the rootlets in the peripheral segment at or distal to the transitional zone (Berthold, Carlstedt and Corneliuson 1993) and, in more severe cases, avulsion from the cord itself which is associated with a partial Brown-Séquard syndrome.

The constant pain probably arises from the disinhibition of neurones within the substantia gelatinosa which fire spontaneously (Loeser, Ward and White 1968). The shooting pain, which may respond to such anticonvulsants as phenytoin or carbamazepine, arises from sudden outbursts of ectopic electrical activity in the damaged part of the dorsal horn.

In animal models differences in neuronal function have been recorded after rhizotomy and avulsion. Spontaneous bursts of firing have been observed from cells in lamina $\mathrm{V}$ of the dorsal horn of the spinal cord of the cat after rhizotomy; this begins within hours and can still be recorded after several months. Avulsion produces steady high-frequency firing in lamina V starting several weeks after injury (Ovelmen-Levitt et al 1984; Ovelmen-Levitt 1988). The convulsive pain of injury to the brachial plexus may correlate with the burst pattern of firing. Abnormal bursting patterns after deafferentation are also observed in higher levels of the central nervous system including the thalamus (Rinaldi et al 1991). Transfer of healthy intercostal nerve into trunk nerves of the upper limb may inhibit this abnormal electrical activity. One explanation for the value of intercostal nerve transfer for the relief of pain is that it restores the input from the damaged limb from receptors in muscle or skin, but this view is untenable in cases in which the pain is modified before any reinnervation has occurred, and it may be argued that the input from receptors in the skin of the chest and intercostal muscles was already present.

Other possible mechanisms may be considered. First, pain relief may depend on cortical inhibition initiated by the sight of activity in the formerly paralysed limb since it is well known that mental distraction regularly relieves pain during the period in which it operates. Secondly, it may be a non-specific effect depending on the anaesthetic, on postoperative pain and the use of analgesics, or on suggestion alone. Other operations previously undertaken, however, had produced only transient relief of pain, never permanent alleviation. Thirdly, relief may be produced by the section of functioning but disconnected axons of the posterior root system from which impulses have, in some way, reached the central nervous system. Further study is required, but we have been pleased to achieve lasting relief from pain by a relatively simple procedure.

Possible reasons for failure of the operation may include disruption of the suture line, damage to the intercostal nerves from severe fractures of the ribs at the time of the original injury, or damage to the ascending fibres of the intercostal nerves in the dorsal columns in the severe avulsion injuries which cause Brown-Séquard syndrome.

Intercostal nerve transfer is a relatively innocuous operation which is likely to alleviate severe pain after preganglionic injury of the brachial plexus. We recommend its use before any more hazardous intervention on the spinal cord or brain is considered.

The authors choose not to respond to the request for a conflict of interest statement.

\section{REFERENCES}

Berthold C-H, Carlstedt T, Corneliuson O. The central-peripheral transition zone. In: Dyck PJ, Thomas PK, eds. Peripheral neuropathy. 3rd edition. Philadelphia: WB Saunders, 1993;1:73-91.

Bonney G. Prognosis in traction lesions of the brachial plexus. $J$ Bone Joint Surg [Br] 1959;41-B:4-35.

Loeser JD, Ward AA, White LE. Chronic deafferentation of human spinal cord neurons. J Neurosurg 1968;39:48-50.

Nagano A, Tsuyama N, Ochiai N, Hara T, Takahashi M. Direct nerve crossing with the intercostal nerve to treat avulsion injuries of the brachial plexus. J Hand Surg 1989;14-A:980-5.

Ovelmen-Levitt J. Abnormal physiology of the dorsal horn as related to the deafferentation syndrome. Appl Neurophysiol 1988;51:104-16.

Ovelmen-Levitt J, Johnson B, Bedenbaugh P, Nashold BS Jr. Dorsal root rhizotomy and avulsion in the cat: a comparison of long term effects on dorsal horn neuronal activity. Neurosurgery 1984;15:921-7.

Rinaldi PC, Young RF, Albe-Fessard D, Chodakiewitz J. Spontaneous neuronal hyperactivity in the medial and intralaminar thalamic nuclei of patients with deafferentation pain. J Neurosurg 1991;74:415-21.

Wynn Parry CB. Pain in avulsion lesions of the brachial plexus. Pain 1980;9:41-53.

Yeoman P. Surgical disorders of peripheral nerves. 2nd edition. In: Seddon H, ed. Edinburgh: Churchill Livingstone, 1975. 